\title{
Auto-Suficiência Energética e Desenvolvimento: o Comércio de Gás Natural entre Brasil e Bolívia
}

\author{
Clara Bonomi Barufi, \\ Edmilson Moutinho dos Santos e \\ Cristiane Reis Ide*
}

Resumo: Este artigo pretende discutir o posicionamento brasileiro diante da crise da nacionalização das reservas bolivianas, tendo em vista o cenário global de preocupação com a segurança energética e também as relações comerciais entre o Brasil e seus vizinhos. Pretende-se sugerir que a busca da autosuficiência gasífera pode não ser a melhor alternativa para o Brasil lidar com a nacionalização boliviana. Ainda que se reconheça que o momento político não é favorável e que os dois países necessitam restabelecer um novo equilíbrio em suas relações, o comércio gasífero entre Brasil e Bolívia deveria ser entendido como uma possibilidade de ampliação da integração econômica e política das duas nações. Além disso, o gás natural importado é um elemento da segurança energética de longo prazo ao qual o Brasil não deve renunciar.

Palavras-chave: Bolívia, Gás Natural, Nacionalização, Relações Comerciais, Segurança Energética.

Abstract: This article aims to discuss the Brazilian position over the nationalization of Bolivian oil and natural gas reserves, considering the global scenario of concern about energy security and also the commercial relationship between Brazil and its neighbors. It aims to suggest that the pursuit of selfsufficiency in natural gas may not be the best alternative for the country in face of the nationalization process taken in Bolivia. Although it is important to realize that the political moment is not appropriate and that both countries need to establish a new equilibrium in their relationship, the commerce of natural gas should be considered as an opportunity to further political and economic integration between the countries. Besides, Brazil should consider imported natural gas as a long term energy security element the country should not renounce.

Keywords: Bolivia, Natural Gas, Nationalization, Commercial Relationship, Energy Security.

* Clara Bonomi Barufi: Mestranda do Programa Interunidades de Pós-Graduação em Energia da Universidade de São Paulo. E-mail: clara@iee.usp.br. Edmilson Moutinho dos Santos: Professor Associado do Instituto de Eletrotécnica e Energia da Universidade de São Paulo. E-mail: edsantos@iee.usp.br. Cristiane Reis Ide: estudante de Engenharia da Escola Politécnica da Universidade de São Paulo. E-mail: cris.ide@gmail.com. Recebido em 01/11/06 e aceito em 08/12/06. 


\section{Introdução}

A segurança energética hoje é um dos assuntos que mais preocupa os governos de todo o mundo. O tema vem ganhando força neste início de século XXI impulsionado pela inevitável e crescente dependência dos países mais desenvolvidos em relação ao petróleo e ao gás natural de zonas como o Oriente Médio e a Rússia. Nessa lógica, os países mais desenvolvidos sentemse vulneráveis e percebem que devem acomodar os interesses dos países exportadores de energia em um jogo geopolítico cada vez mais complexo. A Rússia tornou-se peça chave nesse novo quebra-cabeça, revitalizando suas ambições de superpotência.

O Reino Unido, por exemplo, vê com preocupação as perspectivas de, nos próximos anos, tornar-se um importador líquido de gás natural, deixando de ocupar a privilegiada posição de exportador do insumo (STERN, 2004). O autor lembra que, nos anos 1980, o país importava mais do que $30 \%$ do gás que consumia. Naquele momento, no entanto, isso não representava uma preocupação para a sociedade britânica. A diferença é que, atualmente, o gás responde por mais de $40 \%$ da demanda energética do país, em comparaçáo com menos de $25 \%$ duas décadas atrás, o que aumenta a sua vulnerabilidade com relação ao combustível.

Entre 1998 e 2006, o preço do petróleo elevou-se de cerca de US\$ 10 para mais de US\$ 70 por barril, ou seja, um crescimento superior a $85 \%$ ao ano em um período no qual a inflação em dólares não superou os 2\% ao ano. Além disso, o consumo de petróleo das naçóes tem sido praticamente inelástico. Portanto, tem havido uma grande transferência de renda dos países importadores aos exportadores de energia, resgatando o poder financeiro destes, patrocinando a recuperação do seu crescimento econômico e alimentando-lhes desejos de maior participação nas decisóes políticas globais.

O Brasil acreditou que estaria imune a esses sentimentos de insegurança energética presentes em boa parte do mundo neste início do século XXI. Afinal, em 2006, anunciou sua tão almejada auto-suficiência em petróleo. Além disso, o aumento brutal dos preços do petróleo somado ao desenvolvimento dos veículos flexíveis, que podem usar tanto álcool como gasolina, abriu novas opções para o desenvolvimento de biocombustíveis no país. Hoje o 
Brasil prepara-se para tornar-se um exportador líquido de energia.

Dentrodesse cenário extremamente otimista, os brasileiros surpreenderamse com o acirrar de uma crise gasífera com a Bolívia. Entre 2005 e 2006, com a chegada do presidente Evo Morales ao poder, a Bolívia decidiu nacionalizar suas reservas de petróleo e gás natural. Além disso, exigiu um aumento de mais de $50 \%$ no preço do gás exportado ao Brasil.

Embora a nacionalização já estivesse prevista, tendo sido anunciada nos vários discursos de campanha presidencial de Evo Morales, causou grande desconforto à Petrobras, ao governo do presidente Luiz Inácio Lula da Silva e a diversos segmentos da população brasileira. De repente, o país percebeuse mergulhado no ambiente global da insegurança energética. Em particular, a temática da "segurança energética" tornou-se prioritária entre os atuais ou potenciais consumidores do gás natural exportado pela Bolívia.

Diante de um "quase pânico energético" e um certo sentimento de "ter sido traída pela Bolívia", a resposta da Petrobras tem sido de demonstrar que o Brasil dispóe de alternativas de suprimento de gás. A empresa está antecipando investimentos programados para as Bacias de Campos, Santos e Espírito Santo. A Agência Nacional do Petróleo, Gás Natural e Biocombustíveis (ANP) vem aumentando o foco em áreas com potencial de gás natural nas rodadas de licitações que promove.

Essas medidas indicam que se consolida, entre os formuladores da política energética brasileira, o objetivo de se buscar a auto-suficiência brasileira também em gás natural. $O$ próprio presidente Lula sugeriu, em maio deste ano, que o gás boliviano é dos bolivianos e que o Brasil deveria procurar seus próprios caminhos.

O objetivo deste artigo é discutir esse posicionamento brasileiro diante da crise da nacionalização das reservas bolivianas, tendo em vista o cenário global de preocupação com a segurança energética e também as relações comerciais entre o Brasil e seus vizinhos.

Pretende-se sugerir que a busca da auto-suficiência gasífera pode não ser a melhor alternativa para o Brasil lidar com a nacionalização boliviana. Ainda que se reconheça que o momento político não é favorável e que os dois países necessitam restabelecer um novo equilíbrio em suas relações, o comércio gasífero entre Brasil e Bolívia deve ser entendido como uma possibilidade de 
ampliação da integração econômica e política das duas nações. Além disso, o gás natural importado é um elemento da "segurança energética" de longo prazo ao qual o Brasil não deve renunciar.

\section{Histórico das relações entre o Brasil e a Bolívia}

Desde os anos 1940, o Brasil já discutia com seus vizinhos a possibilidade de importar gás natural. Já naquele momento a Bolívia estava entre os interlocutores. Porém, é curioso notar que, nos anos 1970, com a crise energética mundial, o gás natural não despontou como alternativa energética para o Brasil. As escolhas energéticas brasileiras dos anos 1970/80 privilegiaram principalmente o aproveitamento dos recursos domésticos.

Naquelaépoca, o sentimentodeinsegurançaenergéticaveio acompanhando de estratégias com forte conteúdo nacionalista. Não se poderia esperar algo diferente de uma ditadura militar. O Brasil voltou-se para políticas que privilegiaram a auto-suficiência energética, incluindo: (i) o crescimento da exploração e produção de petróleo doméstico; (ii) a construção de grandes hidroelétricas, com sua integração através de um sistema interligado de transmissão cobrindo as principais regiôes do país; (iii) o programa nuclear (que visava a construção de grandes termelétricas operando na base); e (iv) o programa do álcool combustível.

O gás natural não foi incluído entre essas possibilidades de o país vencer a crise energética dos anos 1970/80. Pelo contrário: as decisóes da política energética naquele momento limitaram a esfera de competitividade do gás natural no mercado nacional. Isso não só complicou o caminho do gás importado como também fez com que a Petrobras desprezasse os campos de gás que descobriu no país. Durante muito tempo, a estatal limitou-se a usar o gás natural para suprir as necessidades das plataformas off-shore. O restante do gás associado ao petróleo era queimado em flares ou reinjetado.

O combustível só começou a fazer parte da agenda política brasileira a partir do início dos anos 1990. Pode-se sugerir que essa mudança de comportamento do Brasil em relação ao gás possa ser explicada pela ameaça de crise de suprimento de petróleo que o país experimentou durante a primeira guerra do Golfo Pérsico em 1990/91, embora não tenham sido encontrados documentos que possam confirmar essa hipótese. 
Como mostra a Figura 1, até o segundo choque do petróleo em 1979/80, a dependência externa energética brasileira era extremamente elevada, aproximando-se a 50\%. A partir de entâo, houve uma rápida redução dessa dependência, chegando-se a menos de $20 \%$ em 1985. Tal conquista foi obtida por meio da substituição das importaçóes de energia por fontes internas, mas também pela desaceleração no crescimento do consumo. Uma vez encerrada a crise energética mundial com o colapso dos preços do petróleo em 1985/86, a demanda e as importações energéticas brasileiras voltaram a acelerar, impelindo a dependência externa energética rumo a uma longa curva ascendente: em 1997, ela quase atingiu o patamar de 35\%. Entre 1998 e 2005, a dependência externa energética brasileira caiu para menos de $15 \%$.

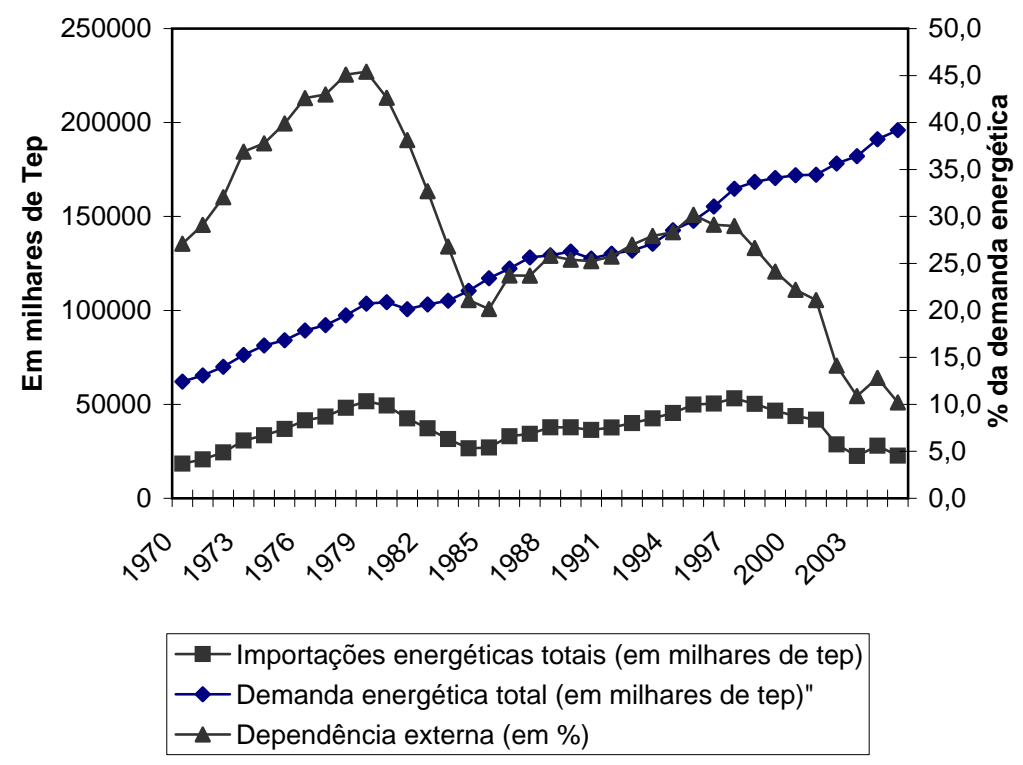

Figura 1 - Evoluçáo da dependência energética externa do Brasil FONTE: MME, 2006 
Durante a primeira guerra do Iraque, em 1990/91, a dependência externa energética brasileira era de cerca de $25 \%$ e encontrava-se em ascensão. Além disso, como mostra a Figura 2, as importaçóes de petróleo ainda representavam cerca de $80 \%$ dessa dependência. O Brasil era um grande importador de petróleo do Iraque, país com o qual o Brasil mantinha uma longa relação de Estado a Estado. Em 1989, por exemplo, aquele país forneceu 42,6\% do petróleo importado pelo Brasil, de acordo com dados do Ministério do Desenvolvimento, Indústria e Comércio Exterior. Essa relação havia sido construída durante os regimes militares que vigoraram nos dois países e também havia permitido ao Brasil exportar ao Iraque (e a outros países do Oriente Médio através do Iraque) matérias-primas, produtos manufaturados e serviços, incluindo serviços de engenharia e armamentos.

Assim, do ponto de vista da segurança energética, o Brasil talvez tenha sido um dos países que mais sentiram os efeitos negativos da guerra e das imposiçóes de sançóes às exportaçóes iraquianas pela Organização das Naçóes Unidas. O pânico em relação a uma eventual ruptura de suprimento energético levou o então presidente brasileiro, Fernando Collor de Mello, a adotar medidas importantes. Em 1991, foi votada a lei que obrigava o governo brasileiro a construir reservas estratégicas de petróleo (tal lei jamais foi implementada). Também procurou-se conter a expansão do consumo e das importaçóes de energia. Entre as medidas tomadas nesse sentido, destacase a Lei 8.176, que impôs restriçôes ao uso de gás liquefeito de petróleo (GLP) em motores, saunas, caldeiras e sistemas de aquecimento de piscinas. Naquela época, em torno de $80 \%$ do GLP consumido no país era importado. Tais medidas foram facilitadas pelas restriçóes econômicas impostas pelo Plano Collor para conter a inflação. Por outro lado, liberou-se a Petrobras para investir no aumento da produção do petróleo doméstico. 


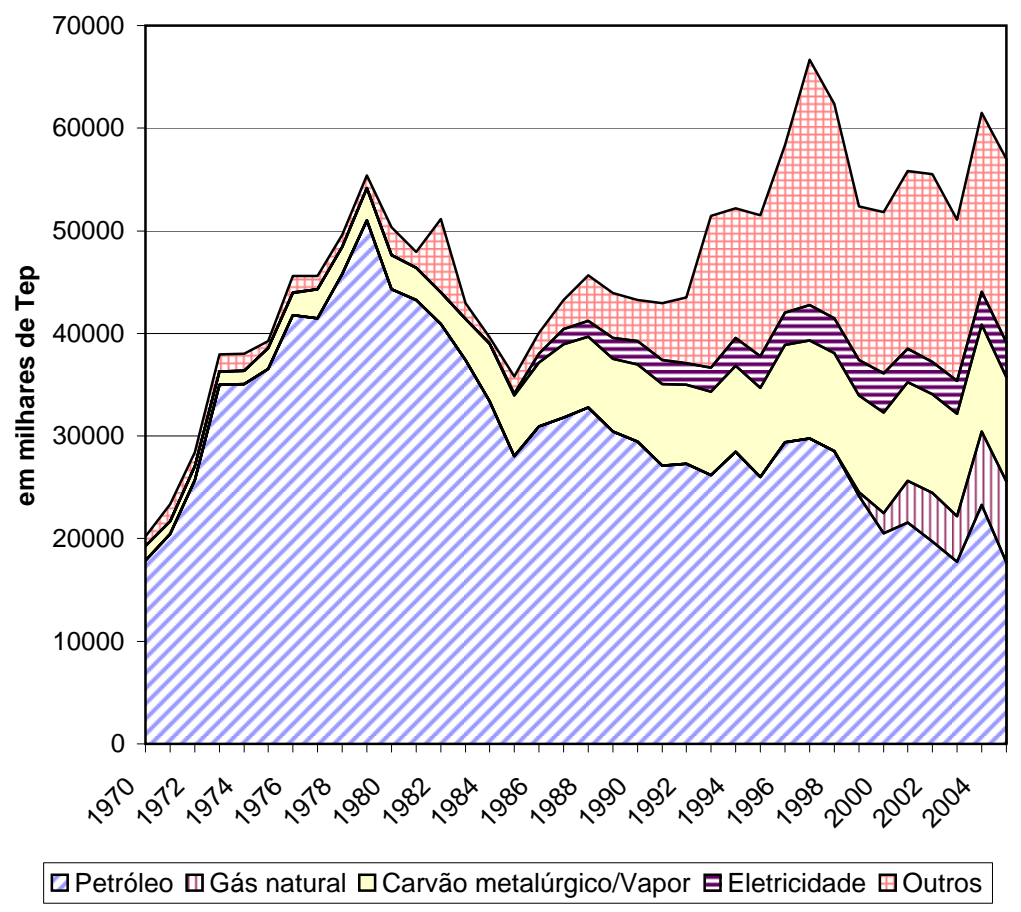

Figura 2 - Evolução das importaçóes de energia FONTE: MME, 2006

Nota: A manutenção de importaçóes significativas de petróleo se deve ao fato de que a auto-suficiência do país nesse produto, atingida em 2006, é verificada apenas em termos líquidos. Em 2005, o Brasil exportou 27,7 milhóes de TEP de petróleo e derivados e importou pouco mais - 28 milhóes de TEP.

Nessa época, o Brasil começou a alterar a sua "dialética da segurança energética", deixando de focar estritamente no conceito de segurança energética como sinônimo de "auto-suficiência energética", para promover a integração energética regional como um substituto da sua dependência externa energética global. Assim, a Petrobras diversificou suas importaçóes de petróleo, priorizando supridores tais como Argentina, Venezuela, Nigéria e Angola. As importaçóes de eletricidade do Paraguai continuaram a aumentar 
na medida em que novas turbinas de Itaipu Binacional eram comissionadas. As importaçóes de carvão para o setor siderúrgico também cresceram, incluindo a Colômbia e a África do Sul como fornecedores. É dentro desse quadro que se pode interpretar a decisão brasileira de construir o gasoduto interligando o Brasil com a Bolívia.

O gás natural boliviano entrou definitivamente na agenda da política energética brasileira em 1992, quando Collor assinou os primeiros contratos com o governo boliviano. No estado de São Paulo, empresas de construção e de equipamentos mobilizaram-se no sentido de viabilizar a obra. Essas negociações acabaram sendo paralisadas por conta da da crise institucional do governo Collor, encerrada com seu impeachment. Porém, quando o presidente Itamar Franco assumiu o governo, tendo Fernando Henrique Cardoso como Ministro de Relaçóes Exteriores, a cartada final do gás boliviano foi jogada. A Petrobras, inicialmente pouco influente no processo, conseguiu recuperar o papel de liderança no projeto, tornando-se o seu principal agente promotor e financiador.

Aos poucos, a decisão de construir o gasoduto tornou-se irreversível. Ainda no início dos anos 1990 e a obra passou a ser considerada como uma solução plausível para o Brasil aumentar sua segurança energética. O gasoduto Bolívia-Brasil (Gasbol), de 3.150 quilômetros e com uma capacidade de transporte de até 30 milhóes de metros cúbicos de gás por dia, entrou em operação comercial em 1999. Foram investidos US\$ 2 bilhóes na obra.

$\mathrm{O}$ gasoduto colaborou para uma substancial diversificação da matriz brasileira de importação de bens energéticos, colaborando com o aumento da segurança energética do país.

Nesse quadro, não deixa de ser surpreendente que o gás boliviano tenha se tornado, aos olhos de muitos brasileiros, a principal fonte de insegurança energética do país, exigindo-se mudanças de comportamento da Petrobras em relação ao suprimento de gás. As pressões eram no sentido de se reduzir a dependência brasileira em relação ao gás importado da Bolívia, substituindoo por produçóes crescentes de gás natural doméstico.

A explicação para essa preocupação crescente está ligada ao rápido crescimento do mercado brasileiro de gás (embora muito inferior ao potencial) e ao fato de o gás boliviano responder por uma fatia significativa 
desse mercado. Sob essa ótica, é compreensível a preocupação crescente do Brasil em relação a uma fonte de suprimento energético que se revela politicamente instável.

Como pode ser visto na Tabela 1 , até 2005, o Brasil apenas importou gás da Argentina e, principalmente, da Bolívia. De 1999 a 2005, o crescimento médio das importaçóes gasíferas bolivianas foi de mais de $180 \%$ ao ano. No caso da Argentina, depois do início das importações para suprir a termelétrica de Uruguaiana em 2001, o país passou a enfrentar os seus próprios problemas de abastecimento, fazendo com que as importaçóes brasileiras diminuissem de maneira considerável entre 2002 e 2005, conforme mostra a tabela abaixo.

Tabela 1 - Importaçóes brasileiras de gás natural, segundo países de procedência - 19992005 (em milhóes de metros cúbicos por ano)

\begin{tabular}{|c|c|c|c|c|c|c|c|c|c|}
\hline \multirow[t]{2}{*}{ Países } & & & & & & & & $\begin{array}{c}\text { Var. } \% \\
\text { no } \\
\text { período }\end{array}$ & $\begin{array}{c}\text { Var. \% } \\
\text { média } \\
\text { anual }\end{array}$ \\
\hline & 1999 & 2000 & 2001 & 2002 & 2003 & 2004 & 2005 & & \\
\hline Argentina & - & 106 & 753 & 492 & 350 & 451 & 279 & & \\
\hline Bolívia & 400 & 2.105 & 3.850 & 4.777 & 5.597 & 7.635 & 8.718 & & \\
\hline Total & 400 & 2.211 & 4.603 & 5.269 & 5.947 & 8.086 & 8.998 & & \\
\hline $\begin{array}{l}\text { Crescimento } \\
\text { anual (\%) }\end{array}$ & & 452,3 & 108,2 & 14,5 & 12,9 & 36,0 & 11,28 & 2149,5 & 168,0 \\
\hline
\end{tabular}

FONTE: ANP, 2006b

Nota: O país começou a importar gás natural em 01/07/99

De acordo com informações da ANP, a participação das importações no mercado brasileiro de gás natural cresceu substancialmente entre 1999 e 2005, passando de 3,3\% da oferta total de gás do país para 33,7\% em 2005. Em 2004, cerca de 54\% de todo o gás comercializado, excluindo o voltado para usos próprios da Petrobras, foi importado, sendo a Bolívia a principal supridora. Em termos físicos, as importaçóes bolivianas representam mais de $80 \%$ do gás comercializado em São Paulo, Mato Grosso do Sul e toda a regiáo Sul do país. O Brasil passou a apresentar uma dependência externa gasífera equivalente àquela que mantinha no início dos anos 1980 em relaçáo ao seu balanço energético como um todo.

Essa situação deixa o país vulnerável às várias instabilidades políticas 
que têm sacudido os países da América do Sul e conturbado suas relaçóes comerciais, com prejuízos particularmente sensíveis na área de gás. Por isso, desde 2005, antes mesmo de concretizada a nacionalização das reservas bolivianas, acentuaram-se debates no sentido do Brasil diversificar suas fontes de suprimento de gás.

Em um primeiro momento, grandes projetos novos de importação foram sugeridos, procurando-se integrar novas áreas de suprimento e reduzir o papel de liderança atualmente exercido pela Bolívia. Planejaram-se, assim, as eventuais construções do Anel Gasífero da América do Sul, que traria gás peruano até o Brasil, e o mega gasoduto que disponibilizaria o gás da Venezuela para o Brasil e para a Argentina. Esse gasoduto representaria uma verdadeira coluna gasífera na América do Sul e teria em torno de 8 mil quilômetros. Há também várias discussôes sobre projetos de importação de gás natural liquefeito (GNL).

O debate tem confundido os analistas, pois as informaçôes são muitas vezes desencontradas ou contraditórias. São projetos mutuamente exclusivos, pois não haveria mercado de gás suficiente para absorver todo o potencial de gás a ser suprido. Além disso, se for tomada uma decisão no sentido de se construir um gasoduto como o proposto pela Venezuela, deve-se levar em conta que, em uma situação normal, projetos desse tipo apresentam um longo período de construção. Desse modo, é bastante improvável que possa representar uma solução imediata para a substituição do gás natural boliviano.

O segundo momento foi marcado pelo anúncio do Plano Estratégico da Petrobras para o período 2007 a 2011, no qual estão priorizados investimentos importantes que permitirão a antecipação da produção do gás natural doméstico nas Bacias de Campos, Santos e Espírito Santo. Para todos os efeitos, a Petrobras trabalha com um cenário em que, no início de 2011, produzirá, em média, 74,5 milhóes de metros cúbicos por dia de gás (NEPOMUCENO FILHO, 2006). Atualmente, apenas nas regióes Sul, Sudeste e Centro-Oeste, são comercializados cerca de 40 milhóes de metros cúbicos diários, dos quais 15,8 milhóes são produzidos no país e o restante é importado. Caso a Petrobras atinja tais metas, poderá pelo menos capturar todo o crescimento futuro do mercado, estagnando assim as importaçóes 
bolivianas em no máximo 30 milhóes de metros cúbicos por dia (atual capacidade máxima de transporte do Gasbol).

Contudo, essa nova postura da Petrobras parece entrar em conflito com os interesses geopolíticos mais amplos do Brasil, representando uma verdadeira reviravolta em uma estratégia internacional reforçada desde o início dos anos 1990. As importaçóes de gás boliviano devem ser encaradas dentro de uma ótica geopolítica que ultrapassa os interesses puramente energéticos.

De fato, o Brasil confere, no contexto regional, importância prioritária às relaçóes com a Bolívia, sendo que o Gasbol, para os dois países, representa um novo eixo de referência para uma eventual atração de investimentos e criação de novas atividades produtivas.

Hoje o Brasil é o primeiro parceiro comercial da Bolívia e é considerado por aquele país como fonte privilegiada de investimentos e promissor mercado consumidor de suas riquezas minerais e insumos energéticos. Empresas brasileiras do setor de construção civil operam na pavimentação de rodovias em diversas regióes do país. Essa penetração poderá ser reforçada com o financiamento, por parte do Banco Nacional de Desenvolvimento Econômico e Social (BNDES), de empresas brasileiras que eventualmente vençam concorrências naquele país. Em julho de 2006, o banco anunciou que essa possibilidade estaria disponível para a construção da rodovia Hacia El Norte, que cortará o país de norte a sul. ${ }^{1}$

\section{Nacionalização dos hidrocarbonetos}

Em dezembro de 2005, o líder do Movimento Rumo ao Socialismo (MAS) da Bolívia, Evo Morales, foi eleito presidente do país. De origem indígena como a maioria da população boliviana, Morales chegou ao poder tendo como base principalmente a promessa de que garantir aos pobres uma parte dos ganhos do país com sua principal riqueza, o gás natural. Essa aspiração era uma das principais demandas dos movimentos sociais bolivianos, sendo traduzida como a necessidade de nacionalizar a propriedade dos recursos energéticos nacionais. $\mathrm{O}$ fato de a nacionalização não ter sido colocada em prática já havia sido responsável pela queda de três presidentes desde 2003.

Para cumprir sua promessa, o presidente Morales assinou, no dia primeiro

\footnotetext{
${ }^{1}$ As informações foram obtidas na página http://www.bndes.gov.br/noticias/not114_06.asp
} 
de maio de 2006, o decreto de nacionalização das reservas de petróleo e gás do país. O decreto afirma que as empresas que produzem petróleo e gás na Bolívia deveriam transferir seus ativos para a estatal boliviana Yacimientos Petrolíferos Fiscales Bolivianos (YPFB). Além disso, com base no decreto, a estatal assumiu a comercialização dos hidrocarbonetos, definindo as condiçóes, volumes e preços para o mercado interno, para a indústria e para a exportação. Também estava prevista uma revisão dos contratos com os antigos produtores para que essas empresas pudessem continuar operando no país.

Porém, mais do que apenas a elaboração de novas regras para os projetos de exploração e produção de gás e petróleo no país, a nacionalização envolveu também um grande espetáculo para a população boliviana. Refinarias, campos e outras instalaçôes petrolíferas foram ocupadas pelo exército boliviano. $\mathrm{Na}$ maioria delas, foram fixadas faixas com o texto "Nacionalizado. Propriedade da YPFB - Povo da Bolívia”.

Essas ações tiveram grande impacto psicológico tanto entre os bolivianos como nos brasileiros. Do lado de lá da fronteira, houve comoção popular em todo o país e o presidente Morales chegou a obter índices de aprovação superiores a $80 \%$, criando uma posição política forte para enfrentar a Assembléia Constituinte que estava começando a reformar as instituiçóes do país.

No Brasil, por outro lado, aumentou o temor de que houvesse problemas no fornecimento do gás natural. Logo após o anúncio da auto-suficiência do petróleo, que representou uma vitória da nação em um projeto energético que se estendeu desde meados dos anos 1950, quando a Petrobras foi criada, o Brasil descobria novamente os dissabores do sentimento de insegurança energética.

De acordo com dados do Ministério de Minas e Energia, o gás natural já atingiu uma participação de 9,3\% da matriz energética brasileira, tendo seu consumo sido incitado principalmente pelas importaçóes bolivianas (MME, 2006). Surgiram, então, dúvidas que eventuais rupturas de suprimento ou revisóes exageradas dos preços poderiam quebrar a confiança dos consumidores e paralisar o crescimento do mercado gasífero brasileiro. 


\section{Resposta da Petrobras}

Apesar do receio dos industriais brasileiros que dependem do gás natural, a nacionalização na Bolívia não causou interrupções no fornecimento de gás para o Brasil. Mesmo assim, as notícias da imprensa brasileira a respeito do assunto foram suficientes para deixar os consumidores em pânico. Industriais que dependem do gás natural boliviano em seus processos produtivos ficaram apavorados diante da possibilidade de faltar gás. As conversóes de veículos ao gás natural veicular (GNV) diminuíram sensivelmente. Em resumo, a Bolívia deixou de ser confiável e o gás natural passou a ser visto como um combustível de risco.

Ao mesmo tempo em que tentou acalmar o mercado mostrando que a nacionalização era um direito dos bolivianos, a própria Petrobras suspendeu temporariamente novos investimentos no projeto de expansão da produção de gás na Bolívia. A estatal brasileira planejava ampliar sua produção de gás no país para 40 milhóes e depois 55 milhóes de metros cúbicos por dia, viabilizando, assim, a quase duplicação da capacidade de transporte do Gasbol. Para a Petrobras, o decreto de nacionalização das reservas e ativos inviabilizou novos aportes financeiros, pois a segurança jurídica dos investimentos foi severamente comprometida.

Sem garantia de suprimento de gás, a ANP foi obrigada a cancelar o processo regulatório que permitiria a ampliação do gasoduto BolíviaBrasil. O cancelamento já havia sido recomendado pela Transportadora Brasileira Gasoduto Bolívia-Brasil (TBG), empresa controlada pela Petrobras e operadora do lado brasileiro do Gasbol. Estimativas apresentadas anteriormente pela TBG indicavam que a ampliação teria um custo de até US\$ 1,47 bilhão para uma capacidade adicional de transporte de cerca de 12 milhões de metros cúbicos por dia.

Enquanto negociava as novas condiçóes de atuação no mercado boliviano, a Petrobras tentou acalmar o mercado brasileiro com a identificação de novas fontes de fornecimento de gás doméstico. Cerca de duas semanas depois da nacionalização, a empresa apresentou ao Conselho Nacional de Política Energética (CNPE) uma revisão preliminar de seus planos estratégicos para antecipar a produção de reservas brasileiras, de modo a diminuir a dependência do gás boliviano. Segundo esse novo plano, a Petrobras deverá, 
já em 2008, ofertar no mercado nacional uma produção adicional de 24,2 milhôes de metros cúbicos por dia de gás natural. Isso é pouco menos que os 25 milhões de metros cúbicos que foram, em média, importados da Bolívia em 2005.

Com esse movimento, a estatal procura traçar na área de gás a mesma linha cumprida para o petróleo, conforme informa o gerente geral de Estratégia e Gestão de Portfólio de Exploração e Produção da empresa, Hugo Repsold (VIGLIANO, 2006b). Segundo ele, a rigor o esforço da Petrobras para mapear as reservas de gás do país ainda não leva o selo da auto-suficiência: trata-se de um esforço semelhante ao empreendido no início dos anos 1980 com relação ao petróleo, cujo objetivo, no início, era maximizar a produção para aproveitar as oportunidades comerciais que se abriam.

Esse reforço na produção nacional deverá vir da antecipação do aproveitamento de reservas já conhecidas do insumo em campos localizados nas Bacias de Campos, Santos e do Espírito Santo. Dentro dessa perspectiva, a Petrobras pretende atingir, no final de 2010, a produção de aproximadamente 74,5 milhóes de metros cúbicos por dia. A maior parte disso (55 milhóes de metros cúbicos) será produzida na região Sudeste, nas bacias de Campos, Santos e Espírito Santo. Outros 12,8 milhóes devem ser obtidos dos campos do Nordeste (NEPOMUCENO FILHO, 2006).

A diversificação das fontes de fornecimento de gás também inclui o ingresso do país na rota dos navios de gás natural liquefeito (GNL). Além disso, a empresa também pretende aproveitar outros energéticos para o abastecimento de suas termelétricas, um dos principais destinos anteriormente previsto para o gás natural doméstico e importado. Apesar disso, a Petrobras se compromete a manter a importação de até 30 milhóes de metros cúbicos diários de gás da Bolívia conforme prevê o contrato que vai até 2019.

Em relação ao GNL, os projetos da empresa indicam que o Brasil poderá importar até 30 milhóes de metros cúbicos por dia de GNL. Essa é a meta da empresa para 2010. Porém, a partir de 2008, a Petrobras já estaria importando cerca de 21 milhóes de metros cúbicos diários. A maior parte desse gás poderá ser negociada por meio de contratos flexíveis, que permitam que se desviem carregamentos de outros países para cá em períodos de seca, quando é necessário o despacho das usinas termelétricas a gás. 
O GNL será trazido, pelo menos inicialmente, em navios com unidades de regaseificação embarcada. Até meados de 2008, serão instalados dois terminais - um na Baía de Guanabara (Rio de Janeiro) e outro no Porto de Pecém (Ceará) -, com capacidade de processar, respectivamente, 14 milhóes e 7 milhóes de metros cúbicos de gás por dia. A Petrobras vai investir US\$ 179 milhões nos terminais. Além disso, a empresa está estudando a possibilidade de implantar outros três terminais no país, em Aratu (BA), São Luís (MA) e São Francisco do Sul (SC).

Com relação às termelétricas, a empresa pretende reduzir suas demandas por gás. Nesse sentido, prossegue com seus esforços para transformar as usinas em bi-combustíveis. A estatal tem trabalhado para que as usinas possam funcionar com óleo combustível ou diesel, ou mesmo álcool, além do gás natural, para que possam ficar à disposição do Operador Nacional do Sistema Elétrico (ONS) para um eventual despacho mesmo sem a garantia de suprimento de gás.

Tudo isso indica que o mercado brasileiro poderá passar, nos próximos anos, de uma situação de "percepção de escassez de suprimento" verificada hoje para uma situação de "superoferta real de gás".

\section{Vantagens da auto-suficiência}

A Petrobras informa que vai apenas manter o atual contrato de importação de gás da Bolívia, o qual prevê o fornecimento de até 30 milhóes de metros cúbicos por dia do insumo até 2019. Boa parte dos consumidores de gás brasileiros preferiria que a estatal também atingisse a auto-suficiência em gás, assim como obteve, pelo menos em termos líquidos, com o petróleo. $\mathrm{O}$ Presidente Luiz Inácio Lula da Silva também defendeu a independência do Brasil em relação às fontes de energia importadas: “Temos de ser donos do nosso nariz. O Brasil tem condições e, portanto, nós vamos trabalhar para que o Brasil seja auto-suficiente", afirmou o presidente em seu programa de rádio Café com o Presidente do dia 15 de maio de 2006.

A principal vantagem da auto-suficiência de gás seria a segurança do abastecimento interno sem que o mercado doméstico fosse influenciado por problemas internacionais. Em seus comunicados sobre a auto-suficiência em petróleo, a Petrobras também dá dicas de como poderá encarar essa condição 
em termos de gás: "A auto-suficiência vai resguardar o consumidor brasileiro, nos momentos de elevada volatilidade dos preços internacionais, como está ocorrendo agora. As flutuaçóes do mercado poderão ser administradas com menor pressão, em um cenário de produção interna superior à demanda. Essa situação interna confortável de equilíbrio no setor energético é privilégio de poucos países industrializados do mundo que, na sua maioria, têm grande dependência do petróleo. (...) Com a auto-suficiência, a Petrobras (...) ficará praticamente imune a eventuais colapsos internacionais" (PETROBRAS, 2006a).

A independência do petróleo importado foi atingida em abril de 2006, com a entrada em operaçáo da P-50 no campo de Albacora Leste, na Bacia de Campos. A nova plataforma tem capacidade de produção de até $180 \mathrm{mil}$ barris de petróleo por dia. Com ela, a Petrobras e suas parceiras atingiram uma produção média de 1,9 milhóes de barris por dia, ante uma demanda do mercado brasileiro da ordem de 1,8 milhóes de barris diários.

A necessidade de se estabelecer um esforço de longo prazo rumo à autosuficiência petroleira tornou-se evidente na década de 1970, com as duas crises do petróleo (1973 e 1979). A dependência externa, combinada com a alta dos preços do insumo naquela época, levou o Brasil a uma situação de desequilíbrio em sua balança comercial. A busca pela independência energética por meio do desenvolvimento de recursos energéticos doméstico foi considerada a estratégia mais adequada para se re-equilibrar as contas externas do país.

Naquele momento, outros países seguiram caminhos distintos do escolhido pelo Brasil. Alguns optaram por manter as importaçóes de energia, mas, simultaneamente, procuraram aumentar a eficiência no seu uso. Também houve casos em que essa estratégia foi combinada com um aumento na produtividade e na qualidade dos produtos exportáveis, aumentando seu valor agregado e, portanto, seu poder de compra face a um custo de energia crescente, como se verá abaixo.

\section{O que dizem os economistas}

O impacto psicológico da auto-suficiência em gás pode ser grande, mas ela não necessariamente é vantajosa do ponto de vista econômico. Isso 
porque, pelo menos em princípio, ela pode ignorar o conceito de vantagens comparativas do comércio internacional. Ou seja, alguns países têm melhores condiçóes para produzir determinados produtos por conta da disponibilidade de matérias-primas ou ainda do conhecimento tecnológico, que viabilizam sua atuação em determinado segmento produtivo. A eventual diferença de custos de oportunidade para a produção de determinado bem em um determinado país e de outro em um segundo país oferece a possibilidade de um benefício para ambos.

Evidentemente que, para um país com grandes reservas energéticas, que podem ser exploradas a baixo custo, pode ser interessante não só a produção desse insumo para si mesmo como até mesmo a sua exportação. Nesse caso, ele passa a ser mais um competidor no mercado global de bens energéticos.

No caso da relação entre o Brasil e a Bolívia, os dados completos não estão disponíveis, mas pode-se sugerir que os investimentos necessários para o abastecimento interno com gás nacional serão superiores aos que seriam necessários para se ampliar a importação de gás boliviano.

Antes da nacionalização boliviana, trabalhava-se com a possibilidade de ampliar a capacidade do Gasbol em, no mínimo, 12 milhóes de metros cúbicos diários, para atingir-se uma capacidade total de importação de cerca de 45 milhóes, com um custo estimado em US\$ 1,47 bilhão. A estratégia da Petrobras para aumentar o fornecimento de gás nacional para o mercado doméstico exigirá, por outro lado, a antecipação de investimentos. O plano de investimentos da empresa para o período de 2007 a 2011 prevê o desembolso de mais de US\$ 14 bilhóes em projetos de exploração e produção de gás. ${ }^{2}$.

Mais cedo ou mais tarde, esses investimentos na exploração de reservas brasileiras deverão ser realizados. No entanto, sua antecipação poderá estar desviando recursos que poderiam ser destinados a outras açóes, talvez mais urgentes, da Petrobras. Tais ações poderiam incluir investimentos em infraestrutura de distribuição e transporte, bem como em medidas de incitação ao consumo de gás, garantindo um crescimento de demanda que poderia

\footnotetext{
2 Esse valor também inclui os investimentos previstos na área de Abastecimento. No total, os projetos de gás e energia receberão investimentos de US\$22,1 bilhões, dos quais US\$ 4,5 bilhões são de parceiros da estatal. Desse total, US\$ 7,5 bilhões serão aplicados em projetos de gasodutos e termelétricas. $\mathrm{O}$ restante será destinado a projetos de Exploração \& Produção e Abastecimento.
} 
permitir, no futuro, a absorção de uma quantidade crescente do gás nacional e importado a ser suprido.

A auto-suficiência também vai contra a lógica econômica na medida em que não é um sinônimo do desenvolvimento econômico. Geralmente é mais consistente a alternativa de utilização da conta de energia como um instrumento de negociação que facilite a abertura de mercados para os produtos industrializados. Um bom exemplo disso foi o modelo adotado em meados dos anos 1980 pela Coréia do Sul, que, na época, tornou-se o segundo maior importador e consumidor de gás natural do mundo. Em contrapartida, conseguiu abrir mercados para suas próprias exportaçóes de produtos industrializados. Mais recentemente, a China tem adotado estratégia similar. Tendo passado de exportadora líquida de petróleo, no início dos anos 1980, à posição de segundo maior importador, os chineses têm utilizado seu poder de compra de produtos energéticos para estabelecer relaçóes comerciais bilaterais e abrir mercados para a exportação de seus produtos manufaturados. Assim, os dois países asiáticos têm consolidado um papel de destaque no comércio internacional, que se sustenta mesmo após terem se transformado em importadores líquidos de energia.

Tomadores de decisão do governo brasileiro indicam que essa forma de se considerar o assunto poderia ganhar espaço no Brasil. O presidente da Empresa de Pesquisa de Energética (EPE), Maurício Tolmasquim, mostra-se a favor de uma integração envolvendo os insumos energéticos. "Não devemos desprezar os países vizinhos. A dependência é uma via de mão dupla. É positiva do ponto de vista do comércio exterior e da integração regional”, afirmou em entrevista (VIGLIANO, 2006a).

\section{As relações comerciais entre o Brasil e a Bolívia após o Gasbol}

A Bolívia, sendo fortemente dependente da exportação de gás natural, se viu obrigada, ao longo dos anos 1990, a buscar outros meios de escoar sua produção quando a Argentina, antes sua principal importadora, aumentou suas reservas e se tornou auto-suficiente. A partir desse momento, as negociaçóes com o Brasil, que não haviam tido sucesso no passado, 
começaram a fluir, resultando no contrato de compra e venda de gás assinado em 1996.

O gasoduto ficou pronto em 1999, com um fluxo de aproximadamente $3 \%$ (em peso) em relaçao àquele registrado no ano de 2005, mas entrou efetivamente em serviço em 2000, quando já se pode notar uma variaçao significativa na participaçao da Bolívia nas importaçóes brasileiras. Como observado na Tabela 2, embora continue reduzida, essa participação quintuplicou de 1999 para 2000 e, a partir deste momento, só foi crescendo, chegando a 1,35\% do total das importaçóes brasileiras em 2005. 
Tabela 2 - Intercâmbio comercial entre Brasil e Bolívia Importação e a exportação em US\$ e quanto isso representa da Balança Comercial brasileira

\begin{tabular}{|c|c|c|c|c|c|}
\hline Ano & $\begin{array}{c}\text { Exportaçáo } \\
\text { (1) }\end{array}$ & $\begin{array}{c}\text { Participação } \\
\% \\
(2)\end{array}$ & $\begin{array}{c}\text { Importação } \\
\text { (3) }\end{array}$ & $\begin{array}{c}\text { Participaçáo } \\
\% \\
(4)\end{array}$ & $\begin{array}{l}\text { Saldo } \\
(5)\end{array}$ \\
\hline 1985 & 170.883 .586 & 0,67 & 9.655 .155 & 0,07 & 161.228 .431 \\
\hline 1986 & 203.158 .949 & 0,91 & 13.932 .948 & 0,1 & 189.226 .001 \\
\hline 1987 & 223.809 .995 & 0,85 & 14.442 .161 & 0,1 & 209.367 .834 \\
\hline 1988 & 196.273 .224 & 0,58 & 11.272 .469 & 0,08 & 185.000 .755 \\
\hline 1989 & 228.909 .869 & 0,67 & 26.398 .097 & 0,14 & 202.511 .772 \\
\hline 1990 & 181.959 .658 & 0,58 & 35.306 .862 & 0,17 & 146.652 .796 \\
\hline 1991 & 255.955 .140 & 0,81 & 24.601 .309 & 0,12 & 231.353 .831 \\
\hline 1992 & 332.635 .269 & 0,93 & 15.523 .116 & 0,08 & 317.112 .153 \\
\hline 1993 & 430.595 .030 & 1,12 & 19.109 .743 & 0,08 & 411.485 .287 \\
\hline 1994 & 469.996 .984 & 1,08 & 23.331 .364 & 0,07 & 446.665 .620 \\
\hline 1995 & 530.082 .592 & 1,14 & 28.352 .921 & 0,06 & 501.729 .671 \\
\hline 1996 & 531.678 .872 & 1,11 & 62.241 .974 & 0,12 & 469.436 .898 \\
\hline 1997 & 719.964 .853 & 1,36 & 26.279 .024 & 0,04 & 693.685 .829 \\
\hline 1998 & 675.819 .193 & 1,32 & 22.360 .941 & 0,04 & 653.458 .252 \\
\hline 1999 & 442.987 .250 & 0,92 & 23.148 .637 & 0,05 & 419.838 .613 \\
\hline 2000 & 364.329 .837 & 0,66 & 140.288 .782 & 0,25 & 224.041 .055 \\
\hline 2001 & 333.470 .861 & 0,57 & 256.144 .679 & 0,46 & 77.326 .182 \\
\hline 2002 & 420.613 .637 & 0,7 & 395.829 .631 & 0,84 & 24.784 .006 \\
\hline 2003 & 359.757 .872 & 0,49 & 520.432 .027 & 1,08 & -160.674 .155 \\
\hline 2004 & 535.337 .663 & 0,55 & 713.360 .511 & 1,14 & -178.022 .848 \\
\hline 2005 & 580.080 .330 & 0,49 & 989.773 .678 & 1,35 & -409.693 .348 \\
\hline
\end{tabular}

FONTE: Ministério de Desenvolvimento, Indústria e Comércio Exterior

(1)Exportaçôes brasileiras para a Bolívia (em US\$);

(2)Participação da Bolívia no total das exportaçóes brasileiras;

(3)Importaçôes brasileiras da Bolívia (em US\$);

(4)Participaçáo da Bolívia no total das importaçóes brasileiras;

(5)Saldo em US\$.

Enquanto isso, as importaçóes bolivianas de produtos brasileiros não apresentaram grande variação. Conforme mostra a Tabela 3, somente a partir de 2002 foi possível reverter uma tendência de queda nos valores nominais, que se estendia desde 1997. Porém, essas importaçóes jamais representaram 
um valor significativo para o balanço comercial do Brasil.

Sob um olhar boliviano, pode-se acompanhar a evolução da participação do gás natural nas exportaçóes da Bolívia para o Brasil. Em 1999, essa participação foi de apenas 3,6\%. No ano seguinte, essa participação subiu para $13 \%$, tendo atingido os $23,5 \%$, em 2001, e 31\%, em 2003. Em 2005, as exportaçóes para o Brasil já representavam cerca de $40 \%$ do total das exportações bolivianas, sendo que quase $81 \%$ desse total correspondia ao gás natural, enquanto o petróleo representava o segundo produto da pauta de exportações. Sabendo-se que quase um terço do PIB da Bolívia é proveniente das exportações e que o gás natural responde por 36\% deste valor, podese concluir sobre a importância do Brasil para a economia boliviana e o financiamento do seu futuro desenvolvimento, já que este compra $84 \%$ do gás exportado pela Bolívia. ${ }^{3}$

A Tabela 3 mostra ainda que, em paralelo ao crescimento das exportaçóes de gás da Bolívia para o Brasil, houve um aumento considerável das compras de produtos brasileiros por parte dos bolivianos.

Tabela 3 - Balança comercial da Bolívia em relação ao Brasil

\begin{tabular}{|c|c|c|c|}
\hline Ano & Importaçóes & Exportaçóes & Saldo \\
\hline $\mathbf{1 9 9 9}$ & $274.230,00$ & $41.292,00$ & $-232.938,00$ \\
\hline $\mathbf{2 0 0 0}$ & $284.362,00$ & $166.488,00$ & $-117.874,00$ \\
\hline $\mathbf{2 0 0 1}$ & $276.444,00$ & $299.550,00$ & $23.106,00$ \\
\hline $\mathbf{2 0 0 2}$ & $392.450,00$ & $336.568,00$ & $-55.882,00$ \\
\hline $\mathbf{2 0 0 3}$ & $347.793,00$ & $503.959,00$ & $156.166,00$ \\
\hline $\mathbf{2 0 0 4}$ & $485.592,00$ & $716.396,00$ & $229.805,00$ \\
\hline $\mathbf{2 0 0 5}$ & $513.708,00$ & $1.016 .452,00$ & $502.744,00$ \\
\hline
\end{tabular}

FONTE: Instituto Nacional de Estadística - Bolívia

Em milhares de dólares

É evidente que a capacidade de crescimento da economia boliviana e, portanto, a sua capacidade de importar produtos brasileiros, eventualmente com maior valor adicionado, depende necessariamente de manter-se o fluxo de gás e o sistema de financiamento externo que a exportação de gás representa para os bolivianos. Nesse sentido, torna-se bastante paradoxal por parte da política governamental brasileira estimular créditos do BNDES para

\footnotetext{
${ }^{3}$ Essas informações são do Instituto Nacional de Estadística - Bolívia (www.ine.gov.bo).
} 
investimentos brasileiros na Bolívia ao mesmo tempo em que se estimula que a Petrobras busque a auto-suficiência em gás. As negociações com a Bolívia em torno do gás natural exigem necessariamente uma visão articulada, que ultrapassa o domínio energético. Na verdade, o gás natural deveria recuperar o seu papel de articulador de uma maior integração econômica e social dos dois países, rompendo os modelos tradicionais de um país mais industrializado simplesmente adquirindo matéria prima barata de uma nação vizinha menos desenvolvida.

Nesse sentido, é importante destacar que a desconfiança dos consumidores brasileiros com relação à possibilidade de $\mathrm{a}$ Bolívia interromper o fornecimento de gás não faz sentido, pelo menos em termos históricos ou sob a ótica da sensatez das naçóes. O próprio Gasbol é um exemplo de confiabilidade do suprimento do país vizinho, já que o gasoduto opera sem interrupção, exceto por razóes técnicas, desde 1999.

Outro exemplo envolvendo a venda de gás natural boliviano é a relação com a Argentina. Em 1972, entrou em operação o gasoduto YABOG, interligando os dois países, o qual operou por mais de 20 anos sem interrupção. Quando a Bolívia iniciou suas exportaçóes para o Brasil, o YABOG deixou de operar, pois as reservas de gás na Argentina já garantiam sua auto-suficiência. Mas a partir de 2004, com as dificuldades vividas no mercado doméstico, os argentinos voltaram a importar gás boliviano através do YABOG, tendo, inclusive patrocinado sua expansão. Ora, justamente em um momento de crise de suprimento interno, a Argentina encontrou guarida em importaçóes crescentes de gás boliviano.

Além disso, a Bolívia exporta petróleo para e através do Chile, através de um oleoduto que se conecta ao porto de Arica, o qual tem operado sem descontinuidade por mais de 30 anos. O país apresenta, portanto, um excelente histórico de segurança de suprimento.

Além desse histórico, é importante observar ainda que a Bolívia depende das exportaçôes do gás natural para obter seus próprios combustíveis. Isso porque, no país, combustíveis como gasolina e GLP são obtidos a partir dos líquidos presentes no gás natural. Como o país não dispóe de muita capacidade de estocagem, caso o envio de gás natural para o Brasil seja interrompido, também será a produção de combustíveis usados localmente. 


\section{Conclusão}

Uma ampliação das negociações entre o Brasil e a Bolívia passa por dois níveis: as decisões da Petrobras, empresa de controle estatal, mas que também agrega investidores privados, e as decisóes do governo brasileiro.

Em primeiro lugar, é fundamental que o governo boliviano e seus técnicos cumpram os acordos estabelecidos entre as partes e não mais causem sustos entre os negociadores brasileiros por conta de mudança de planos em última hora. Uma melhoria nesse sentido é fundamental para que o Brasil possa ampliar seus investimentos naquele país.

Caso medidas nesse sentido não sejam tomadas, em breve os bolivianos perceberão que a decisão da Petrobras de privilegiar o consumo do gás doméstico, mantendo inalteradas as importaçooes bolivianas, poderá ter impactos relevantes sobre a sua economia e equilíbrio social.

Por outro lado, caso o governo boliviano perceba que precisa encarar com seriedade as relaçóes internacionais, a solução mais eficiente para a Petrobras seria tentar retomar o projeto de ampliação do Gasbol. Conforme visto anteriormente, isso poderia ser mais econômico para a empresa.

As medidas tomadas até agora pela Petrobras indicam que a empresa, além de ampliar os investimentos no país para aumentar sua produção nacional de gás, procurará diversificar as fontes de fornecimento de gás natural. Essa diversificação é louvável sob qualquer ponto de vista, pois colabora com o aumento da segurança energética brasileira. Mas é importante é que essas opçóes sejam também as de menor custo e, nesse caso, há indícios de que a ampliação do Gasbol poderia ser a melhor alternativa.

Dentro da mesma hipótese, as relaçóes comerciais entre os dois países poderiam continuar a se expandir. Com isso, do lado de cá, o consumidor brasileiro poderia ficar mais tranqüilo com relação ao fornecimento do combustível, mantendo seu processo de conversão ao gás, condição absolutamente necessária para que o mercado de gás continue a expandir e absorver as quantidades crescentes do insumo a ser produzido.

Vale lembrar que, apesar das ameaças, não houve interrupção no fornecimento de gás para o Brasil por conta da nacionalização das reservas bolivianas. Assim, dadas as dimensões dessas reservas, a relação gasífera entre Brasil e Bolívia ainda merece ser entendida como a melhor opção que ambos 
os países têm para se assegurar mutuamente um mundo mais confiável do ponto de vista da segurança energética, principalmente quando a realidade em outras áreas do planeta poderá deteriorar-se rapidamente. Nesse caso, a parceria de longo prazo pode permitir que os dois países enfrentem as tormentas globais com importantes vantagens competitivas.

Em termos de governo, essa negociação seria uma chance de se estimular ainda mais as relaçóes comerciais entre os dois países, aumentando os mercados da indústria brasileira no exterior, como já vinha acontecendo desde a entrada em operação do Gasbol. Nessa linha, o país poderia seguir o exemplo da Coréia do Sul citado acima, como forma de promover o desenvolvimento de sua indústria através do intercâmbio de produtos industrializados e energia. Isso porque boa parte dos recursos pagos pelos brasileiros pelo gás boliviano volta ao Brasil na forma de produtos industrializados exportados para lá.

Evidentementequetudo isso dependedeo presidenteMorales compreender que o Brasil é um de seus principais parceiros comerciais e, para manter tal relação, é necessário transmitir confiança aos consumidores brasileiros. Inclusive porque as ações quase beligerantes do presidente boliviano vis-àvis a Petrobras e seus investimentos na Bolívia criaram suspeitas e aguçaram um sentimento de insegurança que antes não existia no Brasil. A Bolívia deixou de ser vista como um parceiro privilegiado para transformar-se em "um inimigo potencial em quem não se pode confiar". Dentro da ótica defendida neste artigo, resta agora aos bolivianos terem mais boa vontade e participarem das negociaçóes com responsabilidade e seriedade. 


\section{Referências Bibliográficas}

AGÊNCIA NACIONAL DO PETRÓLEO, GÁS NATURAL E BIOCOMBUSTÍVEIS (ANP). Posicionamento final da ANP quanto ao andamento do concurso público de alocação de capacidade referente ao gasoduto Bolívia-Brasil, maio 2006a. Disponível em: http://www.anp.gov. $\mathrm{br} /$ doc/gas/concurso_aberto/nota_tecnica_14_2006.pdf. Acesso em: 20 jul. 2006.

. Boletim mensal do gás natural. Vários números, 2006b. Disponíveis em: http://www.anp.gov.br. Acesso em: ago. 2006.

INSTITUTO NACIONAL DE ESTADÍSTICA. Bolívia. Indicadores Econômicos. Disponível em: http://www.ine.gov.bo/. Acesso em: 22 ago. 2006.

KRUGMAN, Paul; OBSTFELD, Maurice. Economia internacional: teoria e política. São Paulo: Makron Books, 1999. 807 p.

LAMEIRINHAS, Roberto. Bolívia nacionaliza petrolíferas e exército do país ocupa Petrobras. O Estado de São Paulo, São Paulo, 2 de maio de 2006.

LIMA, K; FARID, J. Para Petrobras, estatização inclui dívida. O Estado de São Paulo, São Paulo, 4 de maio de 2006.

MINISTÉRIO DAS RELAÇÓES EXTERIORES. Divisão da América Meridional II. Disponível em: www.mre.gov.br/. Acesso em: 22 ago. 2006.

MINISTÉRIO DE MINAS E ENERGIA (MME). Balanço Energético Nacional 2006. Disponível em: http://www.mme.gov.br/site/menu/select_main_ menu_item.do?channelId=1432. Acesso em: 15 jul. 2006.

MINISTÉRIO DO DESENVOLVIMENTO, INDÚSTRIA E COMÉRCIO EXTERIOR. Indicadores e Estatísticas. Disponível em: http://www. desenvolvimento.gov.br/sitio/inicial/index.php e http://aliceweb. desenvolvimento.gov.br/default.asp. Acesso em: 5 jun. 2006.

MONTEIRO, T; MARQUES, G; GOY, L. Governo Lula reconhece soberania da Bolívia e diz que vai negociar. O Estado de São Paulo, São Paulo, 3 de maio de 2006. 
NEPOMUCENO FILHO, F. Exploração de petróleo e gás: investimentos e obstáculos para os próximos anos. In: CONGRESSO BRASILEIRO DE PLANEJAMENTO ENERGÉTICO, 5., 2006, Brasília. Brasília: SBPE, 1 de junho de 2006.

OLIVEIRA, N. Petrobras estuda aumentar investimentos na área de gás, diz diretor da estatal. Agência Brasil, 15 de maio de 2006.

OTTA, L; GOY, L. Até 2008, Brasil vai produzir todo o gás que importa hoje da Bolívia. O Estado de São Paulo, São Paulo, 19 de maio de 2006.

PETROBRAS. Conceito e significado da auto-suficiência. Disponível em: http://www.noticiaspetrobras.com.br/interna.asp?id_editoria=28\&id_ noticia $=1328 \&$ palavra $=20$ de abril de 2006. Acesso em: 10 de jun. 2006. (2006a)

- Petrobras apresenta os investimentos na área de Gás e Energia. Rio de Janeiro, 1 ago. 2006. Disponível em: http://www.noticiaspetrobras.com.br/ interna.asp?id_editoria=22\&id_noticia $=1803 \&$ palavra $=$ g_s $\% 20$ natural $\% 2$ 0and\%20investimentos. Acesso em: 15 ago. 2006. (2006b)

- Conselho de Administraçáo da Petrobras aprova o Plano de Negócios 2007-2011. Rio de Janeiro, 3 jul. 2006. Disponível em: http://www.noticiaspetrobras.com.br/interna.asp?id_editoria=22\&id_ noticia $=1697 \&$ palavra $=$ g_s $\% 20$ explora_o\%20produ_o. Acesso em: 15 ago. 2006. (2006c)

SANTOS, Edmilson. Energia, gás natural \& sustentabilidade. 2004.173 p. Tese (Livre Docência) - Instituto de Eletrotécnica e Energia da Universidade de São Paulo, São Paulo, 2004.

SCHÜFFNER, C. TBG conclui os estudos para ampliar Gasbol. Valor Econômico. 21 de novembro de 2005.

STERN, Jonathan. UK gas security: time to get serious. Energy Policy, v. 32, p. 1967-1976, nov. 2004.

VIGLIANO, R. Próximo passo: a política para o gás. Brasil Energia, n. 305, p. 52, abr. 2006a. 2006b. 